\title{
Environment-friendly Electrolyte to Optimize the Surface Properties of Nitinol Tubes
}

\author{
Yongqi Wang, Zhiyong Li, Xiuting Wei ${ }^{*}$ Xuemin Jing, Zhikang Gong, Chuan Liu
}

Shandong University of Technology, School of Mechanical Engineering, 266 xincun west road, 255049, Zibo, China

*E-mail: wxt@sdut.edu.cn

Received: 25 July 2021 / Accepted: 28 August 2021 / Published: 10 October 2021

Nitinol are widely used in biomedicine, mechanical electronics, daily products, and petrochemicals because of their excellent mechanical properties, high-fatigue resistance, corrosion and wear resistance, and biocompatibility. To improve the surface integrity and biocompatibility of nitinol tubes, a polishing method based on an environment-friendly electropolishing solution was studied. The influence of the electropolishing parameters on the surface quality and the degrees of influence were evaluated using orthogonal and single-factor experiments. The removal of material and wettability of the electropolishing process were also analyzed quantitatively. Results showed the good quality of the polished nitinol tube under the optimal polishing parameters. In addition, the amount of material removed was controlled, and biocompatibility was enhanced.

Keywords: Environment-friendly electrolyte; Nitinol tube; Surface properties; Ra; Electrolytic polishing; SEM

\section{FULL TEXT}

(C) 2021 The Authors. Published by ESG (www.electrochemsci.org). This article is an open access article distributed under the terms and conditions of the Creative Commons Attribution license (http://creativecommons.org/licenses/by/4.0/). 